\title{
Fetal-maternal communication: the role of Notch signalling in embryo implantation
}

\author{
Carly Cuman ${ }^{1, *}$, Ellen Menkhorst ${ }^{1, *}$, Amy Winship ${ }^{1,2}$, Michelle Van Sinderen ${ }^{1}$, Tiki Osianlis ${ }^{3}$, \\ Luk J Rombauts ${ }^{4}$ and Evdokia Dimitriadis ${ }^{1,2}$ \\ ${ }^{1}$ Embryo Implantation Laboratory, Prince Henry's Institute of Medical Research, PO Box 5152, Clayton, Victoria 3180, \\ Australia, ${ }^{2}$ Department of Anatomy and Developmental Biology, Monash University, Clayton, Victoria, Australia, \\ ${ }^{3}$ Monash IVF, Monash Surgical Private Hospital, Clayton, Victoria, Australia and ${ }^{4}$ Department of Obstetrics and \\ Gynaecology, Monash University, Clayton, Victoria, Australia
}

Correspondence should be addressed to E Dimitriadis at Embryo Implantation Laboratory, Prince Henry's Institute of Medical Research; Email: evdokia.dimitriadis@princehenrys.org

*(C Cuman and E Menkhorst contributed equally to this work)

\begin{abstract}
The establishment of a successful pregnancy requires the implantation of a competent blastocyst into a 'receptive' endometrium, facilitating the formation of a functional placenta. Inadequate or inappropriate implantation and placentation is a major reason for infertility and is thought to lead to first-trimester miscarriage, placental insufficiency and other obstetric complications. Blastocystendometrial interactions are critical for implantation and placental formation. The Notch signalling family is a receptor-ligand family that regulates cellular processes as diverse as proliferation, apoptosis, differentiation, invasion and adhesion. Notch signalling is achieved via cell-cell interaction; thus, via Notch, cells can have direct effects on the fate of their neighbours. Recently, a number of studies have identified Notch receptors and ligands in the endometrium, blastocyst and placenta. This review collates current knowledge of this large receptor-ligand family and explores the role of Notch signalling during implantation and placentation, drawing on information from both human and animal studies. Overall, the evidence suggests that Notch signalling is a critical component of fetal-maternal communication during implantation and placentation and that abnormal Notch expression is associated with impaired placentation and pre-eclampsia. Reproduction (2014) 147 R75-R86
\end{abstract}

\section{Introduction}

Establishment of a successful pregnancy requires implantation of a competent blastocyst into a 'receptive' endometrium, facilitating the formation of a functional placenta (Fig. 1). Inadequate or inappropriate implantation and placentation is a major reason for infertility (Dimitriadis et al. 2005, Koot et al. 2011) and is thought to lead to first-trimester miscarriage, placental insufficiency and other obstetric complications (Aplin 2010, Knofler 2010). 'Unexplained' infertility accounts for $25 \%$ of couples unable to conceive (Cahill \& Wardle 2002). Additionally, even if embryos undergo chromosome screening and fresh embryo transfer, 33\% will still fail to implant during IVF (Scott et al. 2013). Implantation failure in these cases is predominantly attributed to a non-receptive endometrium (Norwitz et al. 2001). Blastocyst-endometrial interactions are critical for implantation and placental formation; however, very little is known about human blastocystendometrial interactions, predominantly due to the difficulty in studying implantation in humans.
Recently, a number of studies have identified endometrial, blastocyst and placental expression of many members of the Notch signalling family. This review will assemble current knowledge of this large receptorligand family and explore the role of the Notch signalling family during implantation and placentation. While the expression of Notch in the placenta has been recently reviewed (Zhao \& Lin 2012), this review will focus on the role of the Notch signalling throughout the entire implantation process, highlighting the importance of signalling pathways in establishing implantation and placentation.

\section{Implantation and placentation}

To facilitate successful implantation and placentation, the blastocyst and endometrium must be synchronized the endometrium is receptive to blastocyst implantation for a short time period ( $4-5$ days) during the mid-secretory phase (6-9 days following the luteinizing hormone peak) of the menstrual cycle (Paiva et al. 2009). This is 
A

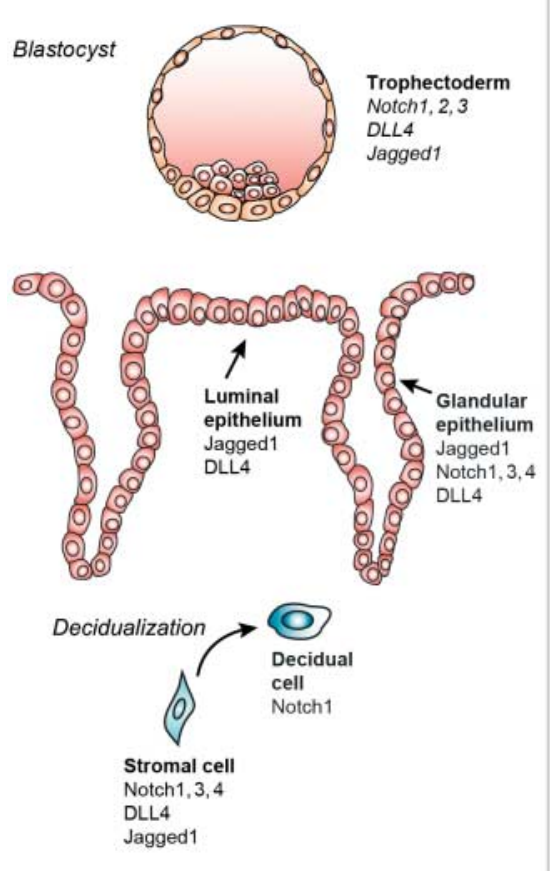

B

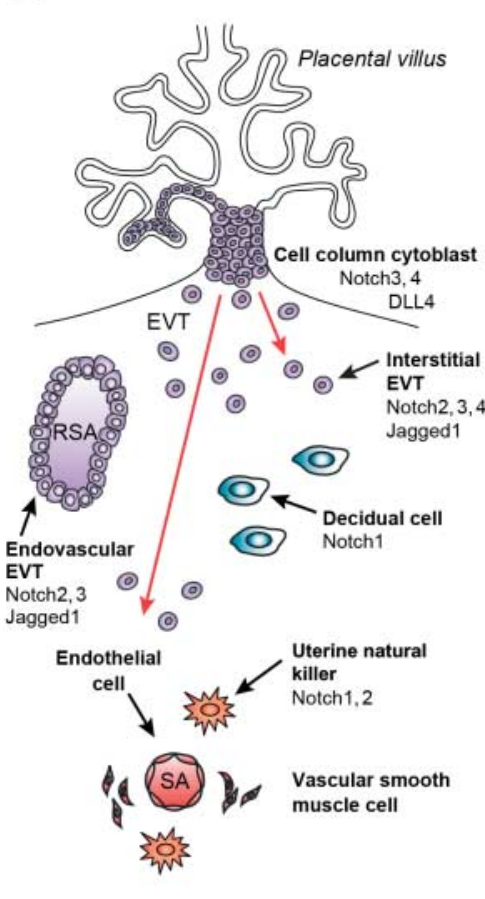

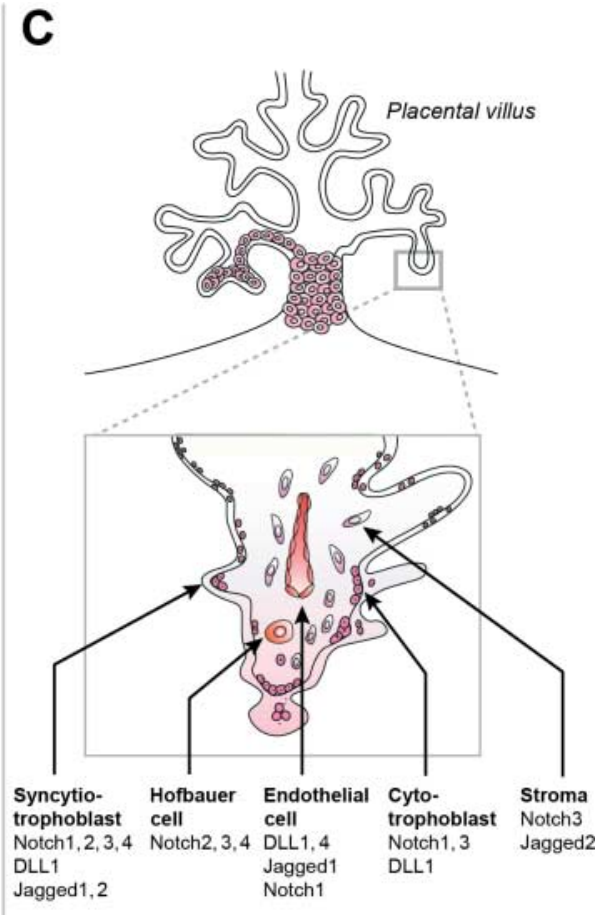

Figure 1 Protein production of Notch receptors and ligands during the establishment of pregnancy. (A) Mid-late secretory phase endometrium showing blastocyst apposition to a suitable region of the luminal epithelium. Trophoblast expression is from mRNA only. Stromal fibroblasts differentiate (decidualize) into decidual cells during the mid-secretory phase of the menstrual cycle regardless of conception/pregnancy. (B) Invasion of extravillous trophoblast (EVT) into the decidua and spiral artery (SA) remodelling during the first trimester. Cytotrophoblast in the cell column differentiate into EVTs, which invade into the decidua (red arrows). SA remodelling is initiated when uterine natural killer cells disrupt SA integrity via interactions with vascular smooth muscle cells. Subsequently, EVTs can invade and replace the SA endothelial cells creating spiral arteries lined by endovascular EVTs - remodelled SA (RSA). (C) Placental villous structure.

referred to as the 'window of implantation'. For the remainder of the menstrual cycle, the endometrium is 'refractory' to implantation.

The uterine endometrium undergoes significant remodelling in preparation for pregnancy during every menstrual cycle (Paiva et al. 2009). Uterine glands differentiate into a highly secretory state, with altered expression of cell surface proteins and adhesion molecules on the apical and basolateral surfaces of the luminal epithelium. Stromal fibroblasts surrounding the spiral arterioles differentiate (decidualize) into morphologically and functionally distinct decidual cells (Fig. 1A; Popovici et al. 2000, Lunghi et al. 2007, Paiva et al. 2009). Immune cells are present in the uterus at all stages of the menstrual cycle, but during the mid-secretory phase associated with the onset of decidualization, there is an influx of macrophages and proliferation of uterine natural killer (uNK) cells (van Mourik et al. 2009, Salamonsen et al. 2009) such that during the first trimester, around $30-40 \%$ of the cells in the decidua are leukocytes (Bulmer et al. 2010). Leukocytes within the decidua are highly specialized compared with peripheral leukocytes (Erlebacher 2013).

The conceptus enters the uterine cavity up to $72 \mathrm{~h}$ prior to implantation (Norwitz et al. 2001) and it is likely that during this time the blastocyst releases soluble factors that interact with the endometrial epithelium to induce or facilitate endometrial receptivity (Fig. 1A; Cuman et al. 2013).

Implantation and subsequent placentation is a continuum involving initially the apposition (Fig. 1A) and subsequent adherence of the blastocyst trophectoderm to the endometrial luminal epithelium. Firm adhesion is the initiating event of implantation - failure of adhesion results in implantation failure or infertility. Following attachment, trophoblast cell proliferation, migration and invasion into the endometrium are critical events that ensure placental development. Cytotrophoblast cells within placenta differentiate into two main cell types: syncytiotrophoblasts and extravillous trophoblasts (EVTs). EVTs within the cell columns proliferate before subpopulations migrate and invade into the decidua. EVT cell migration and invasion are tightly regulated by numerous factors produced within the trophoblastendometrial microenvironment (Salamonsen et al. 2009, Burton et al. 2010).

There are two subpopulations of invasive EVT (Fig. 1B): endovascular EVTs, which initially plug, then remodel maternal spiral arterioles into low resistance, high flow vessels creating the placental blood supply 
at the end of the first trimester (Fig. 1B; Burton et al. 2010), and interstitial EVTs (Fig. 1B), the role of which is unclear. Spiral artery remodelling begins in the absence of any invasive EVTs whereby uNK cells disrupt the vascular smooth muscle surrounding the arteries priming the arteries for EVT colonization (Harris 2011).

The placenta forms the interface between the maternal and fetal circulation. The fetal component of the placenta undergoes extensive morphogenesis to develop villous projections (Fig. 1C). The structure of the chorionic villous increases the available surface area, maximizing fetal-maternal exchange of nutrients, gases and wastes. Villi are lined by trophoblasts and contain a network of fetal capillaries that lead to the umbilical cord, circulating to the developing embryo (Fig. 1C). These villous projections are bathed in maternal blood as a result of EVT arterial remodelling that occurs early in placental development, as aforementioned (Enders \& Carter 2012). During the formation of the placental villi (5-12 weeks gestation), post-proliferative cytotrophoblasts fuse with the overlying syncytium, into which the underlying mesenchyme invades to form the early villi (Kaufmann et al. 1985).

Vasculogenesis describes the formation of new vessels from mesenchymal progenitor cells within these early villi that eventually form the fetal capillaries. Although limited data are available on early villous vascularization in humans, reviewed by Castellucci et al. (2000), this is thought to be the underlying mechanism of placental villous vessel formation. From the $23 \mathrm{rd}$ week of gestation in women, mesenchymal villi transform into mature intermediate villi characterized by reduced cytotrophoblast density and increased capillary density and diameter to ensure efficient exchange (Kaufmann et al. 1985).

\section{Notch signalling}

The Notch signalling pathway regulates diverse cellular processes such as cell invasion, adhesion, survival, apoptosis and differentiation (Artavanis-Tsakonas et al. 1999, Bray 2006, Leong \& Karsan 2006). In humans, there are four Notch receptors (1-4; Chu et al. 2011). Notch receptors are single pass transmembrane proteins composed of a functional extracellular domain (NECD), transmembrane and intracellular domain (NICD) (Hurlbut et al. 2007).

\section{Canonical signalling}

Canonical Notch signalling is achieved via cell-cell interaction, in which Notch receptors expressed on the surface of one cell interact with ligands present on the surface of a neighbouring cell (D'Souza et al. 2010). Signal-sending and signal-receiving cells can be of equivalent or differential cellular type (trans-activation) or alternatively intracellular auto-inhibition can occur within the same cell (cis-inhibition). In humans, there are five membrane-bound ligands: the Delta-like (DLL) 1, 3 and 4 and Jagged 1 and 2 (Kopan \& Ilagan 2009). Canonical Notch ligands are transmembrane proteins containing EGF (Epidermal growth factor)-like repeats in their extracellular domain, as well as a single Delta or serrate \& Lag-2 (DSL) domain necessary for the interaction with Notch receptors (Artavanis-Tsakonas \& Muskavitch 2010, D'Souza et al. 2010). Notch ligandreceptor binding leads to receptor cleavage by proteases, including ADAM (A Distegrin And Metalloprotease) and $\gamma$-secretase, and release of the NCID that translocates to the nucleus, where it binds to Recombining Binding Protein, Suppressor of Hairless (RBPSUH), and induces gene transcription of the Notch target genes (Ilagan \& Kopan 2007, Kopan \& Ilagan 2009), including members of the basic helix-loop-helix and hairy/enhancer of split/-related (e.g. Hes and Hey) families (Mikhailik et al. 2009, Mitsuhashi et al. 2012) and myc, cyclin D and p21 (Bray \& Bernard 2010).

\section{Non-canonical signalling}

The non-canonical signalling pathway is not fully understood. Two signalling pathways have been identified as non-canonical: ligand-dependent and ligand-independent. Non-canonical ligand-dependent signalling refers to membrane-bound and secreted ligands that do not contain the DSL domain (D'Souza et al. 2010, Wang 2011). These proteins act as both ligands and modulators of Notch signalling and are comprehensively described in Wang (2011). Much less is known about non-canonical ligand-independent signalling (Andersen et al. 2012). Recent studies suggest that the normally membrane-bound Notch receptors localize in the cytoplasm and post-translationally target $\mathrm{Wnt} / \beta$-catenin signalling, via binding and titration of active $\beta$-catenin (Andersen et al. 2012). To date, ligand-independent Notch signalling in humans has only been investigated in human embryonic stem cells; however, the available information suggests that ligand-independent signalling is found mainly in stem or progenitor cells across species (Andersen et al. 2012). A comprehensive review of Notch non-canonical signalling has recently been published; therefore, it is not reviewed in the current paper (Andersen et al. 2012).

\section{Notch signalling at the human blastocyst-maternal interface}

\section{Notch signalling in the endometrium}

Much research into the Notch family in the endometrium has focused on its role in disease states such as cancer and hyperplasia due to its roles in proliferation, differentiation and angiogenesis. All four Notch receptors are present in the endometrium (Table 1 and Fig. 1A), 
Table 1 Notch ligand localization in cycling endometrium and blastocyst trophectoderm.

\begin{tabular}{|c|c|c|c|c|c|}
\hline & \multicolumn{4}{|c|}{ Endometrium } & \multirow{2}{*}{$\frac{\text { Blastocyst }}{\text { Trophectoderm }}$} \\
\hline & Luminal epithelium & Glandular epithelium & Stroma & Endothelial cells & \\
\hline Notch1 & & $++^{\mathrm{a}, \mathrm{b}}$ & $+{ }^{a, b}$ & $-^{\mathrm{a}}$ & $\alpha^{\mathrm{C}}$ \\
\hline Notch2 & & $\alpha^{\mathrm{d}}$ & $\alpha^{\mathrm{d}}$ & & $\alpha^{\mathrm{c}, \mathrm{e}}$ \\
\hline Notch3 & & $++^{b}$ & $+{ }^{b}$ & & $\alpha^{\mathrm{e}}$ \\
\hline Notch4 & & $++^{\mathrm{a}}$ & $+^{a}$ & $+^{a}$ & \\
\hline DLL1 & & & & & \\
\hline DLL3 & & & & & $\alpha^{\mathrm{c}}$ \\
\hline DLL4 & $++^{f}$ & $++{ }^{b, f}$ & $+{ }^{b, f}$ & $+{ }^{f}$ & $\alpha^{\mathrm{e}}$ \\
\hline Jagged1 & $+^{g}$ & $++^{a, b}$ & $+{ }^{a, b}$ & $-{ }^{a}$ & \\
\hline Jagged2 & & & & & \\
\hline Hes1 & & $\alpha^{\mathrm{d}}$ & $\alpha^{\mathrm{d}}$ & & \\
\hline Hey1 & & $\alpha^{\mathrm{d}}$ & $\alpha^{\mathrm{d}}$ & & \\
\hline Hey2 & & & & & $\alpha^{\mathrm{e}}$ \\
\hline
\end{tabular}

$\alpha$, mRNA expression; + , present low levels; ++ , present in high levels; - absent; blank, unknown.

${ }^{a}$ Cobellis et al. (2008). ${ }^{b}$ Mitsuhashi et al. (2012). c'Adjaye et al. (2005). ${ }^{d}$ Mikhailik et al. (2009). ${ }^{\mathrm{e}}$ Aghajanova et al. (2012). ${ }^{\mathrm{f}} \mathrm{Mazella}$ et al. (2008).

gCuman et al. (2013).

although Notch2 has only been identified at the mRNA level (Cobellis et al. 2008, Mikhailik et al. 2009, Mitsuhashi et al. 2012, Mori et al. 2012).

Notch1 and 3 protein primarily localize to the glandular epithelium (Cobellis et al. 2008, Mitsuhashi et al. 2012), whereas Notch4 localizes primarily to the stroma (Cobellis et al. 2008). In the only study to examine transcript, Notch1 and 3 expressions are higher in endometrial stromal cells compared with epithelium (Mikhailik et al. 2009); however, this analysis was performed following isolation and culture and therefore may not represent in vivo expression.

Two studies have previously investigated Notch family protein expression throughout the menstrual cycle. Cobellis et al. (2008) identified changes in the expression of Notch1, which was strongest during the mid-secretory phase, and Notch4, which was stronger during the proliferative phase. Conversely, Mitsuhashi et al. (2012) more recently identified no differences in Notch1 and 3 across the cycle. This is despite using the same antibodies for Notch1, albeit at different concentrations. In support of cyclical variation in Notch expression, the expression of Notch1 and 4 correlates with the endometrial expression of downstream Notch target genes: P21 (CDKN1A), an epithelial cell proliferation inhibitor, and cyclin D (Cobellis et al. 2008) a promoter of cell proliferation.

Presently, Jagged1 and DLL4 are the only Notch ligands known to localize to the endometrium (Table 1; Mazella et al. 2008, Mikhailik et al. 2009, Mitsuhashi et al. 2012). Both ligands strongly localize to the endometrial glandular and luminal epithelium, with very little to no expression in the stroma. Jagged $1 \mathrm{mRNA}$ and protein are highest during the mid-secretory phase compared with the proliferative phase (Cobellis et al. 2008, Cuman et al. 2013). Whilst DLL4 mRNA expression is highest during the early secretory phase (Mazella et al. 2008), DLL4 protein shows no significant changes across the cycle (Mitsuhashi et al. 2012). Taken together, the up-regulated expression of these ligands during the mid-secretory phase suggests a role in receptivity. There is very little information regarding the endometrial expression of downstream signalling targets Hes and Hey1. Their mRNA expression is higher in epithelial cells compared with the stromal cells, which correlates with high Jagged1 and DLL4 protein in the epithelium (Mikhailik et al. 2009), suggesting that Notch signalling is active in these cells.

Despite the identification of the presence of both Notch receptor and ligand within the endometrium, there is no evidence that investigates whether juxtacrine activities maybe occurring between the same or different cell types.

\section{Notch signalling in the blastocyst}

Notch1, 2, 3, DLL4, Jagged1 and Hey2 have been identified by microarray studies as present in human blastocyst trophectoderm (Fig. 1A and Table 1; Adjaye et al. 2005, Aghajanova et al. 2012). However, the ethical difficulties in obtaining human blastocysts have limited the functional studies examining blastocystendometrial interactions during the early stages of implantation.

\section{Function of Notch signalling in blastocyst-maternal interactions}

The expression of the Notch receptors and ligands by the trophectoderm and immunolocalization of Notch1, DLL4 and Jagged1 to the apical surface of the luminal epithelium during the mid-secretory phase of the menstrual cycle (Fig. 1A; Mazella et al. 2008, Cuman et al. 2013) highlights the accessibility of Notch ligands and receptors for interactions during endometrial epithelial-trophectoderm attachment (Fig. 1A). In mice, DLL1 is shown to act as an adhesion molecule directly 
regulating mast cell-stromal cell adhesion via binding to Notch2 (Murata et al. 2010). To date, however, no studies have investigated the role of Notch in endometrial receptivity or blastocyst attachment in humans. However, there is reduced or absent immunostaining of Jagged 1 in the mid-secretory luminal epithelium of women with primary infertility (Cuman et al. 2013), suggesting that this ligand may be important for blastocyst-epithelial attachment. Furthermore, microarray analysis demonstrates that blastocyst-conditioned media regulates the endometrial epithelial expression of Notch1 and Jagged1 in vitro (Cuman et al. 2013); thus, blastocysts may facilitate endometrial Notch expression, and possibly endometrial receptivity, via soluble mediators.

\section{Notch signalling in implantation and placentation Tissue localization of Notch family in human placenta and decidua}

To date, only one study has investigated the expression of Notch family members in implantation sites during early implantation and placentation (Table 2 and Fig. 1B; Hunkapiller et al. 2011). The individual expression pattern observed for each protein (Table 2) highlights the possible role that each Notch family member plays in regulating trophoblast differentiation and invasion.

\section{Invasive trophoblast}

No information is available for the expression of Notch family members during the first trimester. During the second trimester (Table 2 and Fig. 1B), Notch1, DLL1 and Jagged2 are absent in all trophoblast lineages. Notch3 is present in all trophoblast lineages. The expression of Notch2 and 4, DLL4 and Jagged1 is associated with the differentiation of cytotrophoblast to invasive EVT lineages: as cytotrophoblast differentiate towards invasive EVT, Notch2 and Jagged1 expression is up-regulated, whereas DLL4 is expressed only by trophoblasts residing in the cell column and Notch4 is down-regulated in EVTs in close proximity to spiral arterioles (Hunkapiller et al. 2011). Interestingly, despite not being identified in EVTs in the second trimester, Notch1, along with Notch4 and Jagged1, is localized to EVTs in third-trimester decidua (De Falco et al. 2007).

\section{Decidua}

Little is known about decidual Notch expression (Table 2 and Fig. 1B). uNK cells express Notch1 and 2 (Manaster et al. 2010). To our knowledge, no study has localized Notch signalling family members in human decidualized stromal cells, except Notch1 ex vivo in decidual cells isolated from term placentas (Afshar et al. 2012b). Immunofluorescence figures highlighting trophoblast expression of Notch family members in Hunkapiller et al. (2011) provide some clues as to decidual Notch expression. Unfortunately, this study does not investigate Notch1 expression. Intriguingly, these data suggest that Notch4, Jagged1 and DLL4 are likely absent from maternal cells in the decidua during the second trimester (Hunkapiller et al. 2011). Notch3 and DLL1 are clearly visible in maternal cells of the decidua; however, from the figures provided, it is not possible to identify the cell types. Strong expression of DLL1 is observed in maternal cells associating with EVTs remodelling spiral arterioles during the second trimester (Hunkapiller et al. 2011); however, the identity of these cells is not clear. These cells are likely either decidual cells or uNK cells; certainly, DLL1 is expressed by uNK cells in mice (Degaki et al. 2012).

\section{Placenta}

Studies examining Notch expression in the placenta are conflicting, with localization studies not showing consistent expression. One study investigating transcript levels of Notch3, 4, Jagged1, 2 and DLL4 found that expression increased from the first to the third trimester

Table 2 Notch ligand localization in the decidua during pregnancy.

\begin{tabular}{|c|c|c|c|c|c|c|c|c|c|c|c|c|c|c|c|}
\hline \multirow{2}{*}{$\begin{array}{l}\text { Notch } \\
\text { members }\end{array}$} & \multicolumn{3}{|c|}{ Decidua } & \multicolumn{3}{|c|}{ Cytotrophoblast cell column } & \multicolumn{3}{|c|}{ EVTS } & \multicolumn{3}{|c|}{ Endothelial cells } & \multicolumn{3}{|c|}{ Immune cells } \\
\hline & $1 \mathrm{st}$ & 2nd & $3 \mathrm{rd}$ & $1 \mathrm{st}$ & 2nd & $3 \mathrm{rd}$ & $1 \mathrm{st}$ & 2nd & $3 \mathrm{rd}$ & $1 \mathrm{st}$ & 2nd & $3 \mathrm{rd}$ & $1 \mathrm{st}$ & 2nd & $3 \mathrm{rd}$ \\
\hline $\begin{array}{l}\text { Notch1 } \\
\text { Notch2 }\end{array}$ & & & $+^{a}$ & & & & & $\begin{array}{l}-{ }^{b} \\
+^{b}\end{array}$ & $++^{c}$ & & & & $\begin{array}{l}+{ }^{\mathrm{uNKd}} \\
+{ }^{\mathrm{uNKd}}\end{array}$ & & \\
\hline Notch3 & & & & & $+{ }^{b}$ & & & $+{ }^{b}$ & & & & & & & \\
\hline Notch4 & & $--^{b}$ & & & $+^{b}$ & & & $+^{b}$ & $+^{c}$ & & & & & & \\
\hline DLL1 & & & & & $-\mathrm{b}$ & & & $-{ }^{b}$ & & & & & & & \\
\hline DLL3 & & & & & & & & & & & & & & & \\
\hline DLL4 & & $-{ }^{b}$ & & & $+{ }^{b}$ & & & $-{ }^{b}$ & & & & & & & \\
\hline Jagged1 & & $-{ }^{b}$ & & & $-b$ & & & $+{ }^{b}$ & $++^{\mathrm{c}}$ & & & & & & \\
\hline Jagged2 & & & & & $--^{b}$ & & & $-{ }^{b}$ & & & & & & & \\
\hline Hes1 & & & & & & & & & & & & & & & \\
\hline Hey1 & & & & & & & & & & & & & & & \\
\hline
\end{tabular}

$\alpha$, mRNA expression; + , present low levels; ++ , present in high levels; - , absent; blank, unknown.

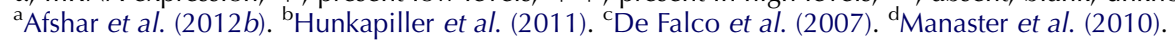


(Herr et al. 2011); however, many studies, investigating a variety of genes, also identify increased gene expression in third-trimester placentas compared with first-trimester placentas, suggesting that this may just reflect a change in global gene expression.

The limited number of studies to date makes it difficult to determine whether there are differences in Notch receptor or ligand protein localization and levels between the first and third trimesters, although the only study to directly compare the two trimesters found no differences (Herr et al. 2011). Further, immunolocalization of Notch receptors and ligands is variable between studies, despite likely using the same antibodies. Generally, however, most proteins are present in both first- and third-trimester tissue with very few factors showing differential staining between the two gestation times (Table 3).

Overall, the more recent studies have less background, suggesting that these studies reflect true positive staining. Therefore, in the text, we refer only to the most recent studies, although all studies are represented in Table 3.

Notch1 is expressed by trophoblasts, certainly syncytiotrophoblasts (Cobellis et al. 2007, De Falco et al. 2007, Herr et al. 2011, Sahin et al. 2011), and possibly cytotrophoblast (Cobellis et al. 2007, De Falco et al. 2007, Herr et al. 2011), but staining is absent in the EVT of the cell column (Table 2; Hunkapiller et al. 2011). Notch2 (Sahin et al. 2011), Notch3 (Herr et al. 2011) and Notch4 (Sahin et al. 2011) are also localized to the syncytiotrophoblasts and Notch3 localizes to the cytotrophoblasts (Herr et al. 2011). DLL1 (Herr et al. 2011) and Jagged 1 and 2 (Sahin et al. 2011) are expressed by syncytiotrophoblast and DLL1 also by cytotrophoblast (Herr et al. 2011). In non-trophoblast lineages, Notch1, Jagged1, DLL1 and DLL4 are expressed by endothelial cells (Herr et al. 2011, Sahin et al. 2011), while Hofbauer cells express Notch2, 3 and 4 (Herr et al. 2011) and Notch3 and Jagged2 localize to the villous stroma (Herr et al. 2011; Table 3).

\section{Function of Notch signalling during implantation and placentation}

\section{Decidualization}

Decidualization describes the terminal differentiation of uterine endometrial stromal cells such that their morphology and function change. Notch1 signalling has been shown ex vivo to be critical for the progression of decidualization; silencing Notch1 in stromal cells isolated from decidua parietalis (decidua of term pregnancy, from a site not associated with the placenta) impaired decidualization in vitro (Afshar et al. 2012b). Furthermore, this study showed that Notch1 is induced by human chorionic gonadotrophin (hCG) and the authors suggest that Notch1 responds to hCG to mediate a survival signal in the uterine endometrium so that menstrual sloughing is avoided. Certainly, Notch1 is a known mediator of survival signals and in mice abrogation of Notch1 signalling during decidualization decreased proliferation and up-regulates apoptosisassociated genes (Afshar et al. 2012b). Intriguingly, a global gene array study identified up-regulation of the Notch signalling pathways in decidual cells exposed to trophoblast conditioned media, suggesting that Notch family members other than Notch1 may regulate decidualization (Hess et al. 2007).

\section{EVT invasion}

While the precise role of Notch signalling in EVT invasion remains unclear, the pattern of Notch family expression during early placentation strongly suggests a role in EVT differentiation and invasion into the decidua (Table 2). Some functional data to strengthen this notion demonstrate that invasion through Matrigel of cytotrophoblasts isolated from term placentas was impaired in the presence of a $\gamma$-secretase inhibitor, which acts to inhibit canonical Notch signalling (Hunkapiller et al. 2011). In the same study, DLL4 was found to be transiently up-regulated during cytotrophoblast invasion in vitro. Meanwhile, the in vivo localization of DLL4

Table 3 Localization of Notch-ligand in placenta.

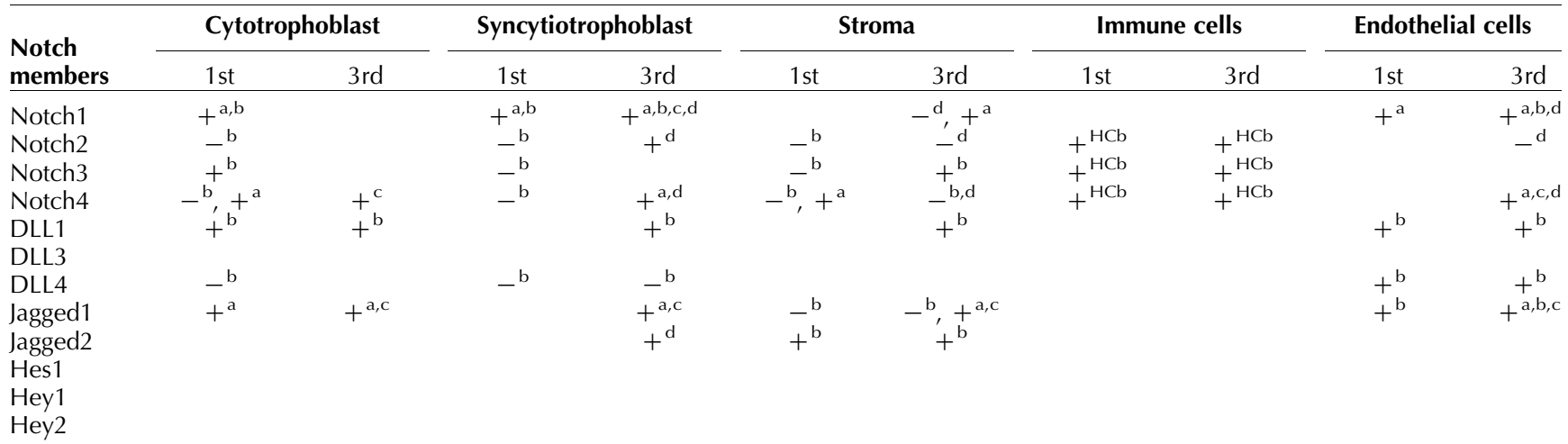

$\alpha$, mRNA expression; + , present low levels; ++ , present in high levels; - , absent; blank, unknown; HC, Hofbauer cell.

${ }^{a}$ De Falco et al. (2007). ${ }^{b}$ Herr et al. (2011). ${ }^{c}$ Cobellis et al. (2007). ${ }^{d}$ Sahin et al. (2011). 
is restricted to cytotrophoblasts in the cell columns (Hunkapiller et al. 2011), suggesting that DLL4 could be involved in the differentiation of cytotrophoblasts towards invasive EVTs, an important step in invasion.

\section{Spiral artery remodelling}

Notch signalling may be critical for spiral artery remodelling. Prior to EVT invasion of spiral arteries, uNK cells act to disrupt the integrity of the arteries, particularly the vascular smooth muscle (Harris 2011). Recently, uNK-conditioned media and interferon- $\gamma$ alone were shown to disrupt vascular smooth muscle cell integrity (Robson et al. 2012), a critical step in spiral artery remodelling. Furthermore, both DLL1 and 4 interact with Notch on uNK cells to induce interferon- $\gamma$ secretion (Manaster et al. 2010). As uNK cells express Notch1 and 2 and DLL1 is expressed by maternal cells surrounding spiral arteries (Hunkapiller et al. 2011) and by uNK cells in mice (Degaki et al. 2012), it is tempting to speculate that Notch activation in $\mathrm{uNK}$ cells is regulated by DLL1, leading to interferon- $\gamma$ secretion and vascular smooth muscle disruption, prior to EVT invasion.

\section{Placentation}

There are few functional studies examining the role of Notch signalling in human placental vasculogenesis. The localization of Notch family members DLL1, 4, Jagged 1 and Notch 1 to the endothelial cells in tertiary villi implies a role in placental vasculogenesis, as recently reviewed (Zhao \& Lin 2012). In addition, Hofbauer cells and cytotrophoblast induce angiogenesis during placental vasculogenesis via the secretion of growth factors (Demir et al. 2007). The localization of Notch receptors 2, 3 and 4 to Hofbauer cells (Herr et al. 2011) in the villous stroma and the ligands to the endothelial cells suggests a role for Notch signalling in angiogenesis, although this remains to be experimentally proven. Certainly, Hofbauer cells are in close contact with endothelial progenitor cells (angiogenic cell cords), during the initiation of vascularization (Seval et al. 2007), potentially allowing direct cell communication via Notch signalling.

Meanwhile, the differential expression of Notch receptors and ligands by the cytotrophoblast compared with syncytiotrophoblasts (Table 3 ) suggests that Notch signalling may play a role in differentiation from cytotrophoblasts to syncytiotrophoblasts or possibly that Notch signalling is involved in interactions between syncytiotrophoblasts and cells in the intervillous space. Differentiation of human embryonic stem cells towards a trophectoderm linage is shown to require inhibition of Notch activation (Yu et al. 2008); however, no studies have investigated differentiation towards the cytotrophoblast or syncytiotrophoblast lineages. Further studies are clearly needed to confirm the function and regulation of Notch signalling in human placentation.

\section{Clues from animal studies}

\section{Pre-implantation development and Notch signalling in mice}

Mice studies have provided clearer identification of Notch signalling in the pre-implanted embryos, with mRNA expression of the different genes identified throughout the stages of embryo pre-implantation development. Notch1, 2, Jagged1, 2, DLL3 and RBPSUH are expressed in oocytes and by the conceptus at all stages of pre-implantation development, while expression of Notch4 and DLL4 was observed only from the two cell stage through to the hatched blastocyst stage. Interestingly, the mRNA expression of NOTCH3, DLL1 and Deltex homologue 1 is stage dependent. Their expression is detected at the two-cell embryo and hatched blastocyst stage, while low or absent at the morula stage (Cormier et al. 2004). Furthermore, in vitro studies demonstrate a role for Notch signalling in mouse blastocyst spreading (Chu et al. 2011) while in vivo studies showed that administration of a $\gamma$-secretase inhibitor disrupts endometrial stromal cell decidualization (occurs post-implantation in mice), leading to pregnancy loss (Afshar et al. 2012a). Thus, in mice, these studies suggest that Notch signalling is important in endometrial epithelial cell function, highlighting the importance of examining blastocyst-endometrial epithelial interactions in humans.

\section{Notch signalling in the mouse placenta}

Mouse placental development involves a number of processes, including trophoblast differentiation, chorioallantoic fusion and branching, fetal vascular morphogenesis and the establishment of a maternal blood supply. Both the human and mouse placenta are haemochorial, where trophoblasts are directly bathed in maternal blood (Watson \& Cross 2005), and both share a high degree of structural, proteomic and molecular genetic homology (Cox et al. 2009, Dilworth \& Sibley 2013).

Several Notch signalling family members are expressed in the mouse placenta. Targeted single-gene mutations in Notch1, 2, 4 and DLL1, 4 result in midgestation embryonic lethality, indicating a pivotal role for this pathway in the formation of a functional placenta, as previously reviewed by Gasperowicz \& Otto (2008).

However, of these family members, only a clearly defined role for Notch2 has been elucidated. Of the Notch receptors, Notch2 is the only receptor upregulated during trophoblast invasion in mice. Notch2 deletion results in embryonic lethality at E11.5 (Hamada 
et al. 1999). Hamada et al. 2007 demonstrated that whole embryo culture evaded lethality in mutant embryos, suggesting an extraembryonic cause. Notch2 localizes to maternal sinusoidal trophoblasts in the mouse placental labyrinth, the site of fetal-maternal exchange, and from the histology of early Notch2deficient placentas, poor maternal blood sinus formation was evident (Hamada et al. 2007). More recently, conditional deletion under the Tpbpa promoter (Simmons et al. 2007) specific for invasive spiral arteriole giant trophoblast Cell (TGC) and glycogen trophoblast cell lineages has shown impaired trophoblast invasion into the maternal arteries and reduced maternal canal size and placental perfusion (Hunkapiller et al. 2011). Taken together, these findings imply a fundamental role for Notch2 signalling in endovascular trophoblast invasion in the mouse placenta.

While previously, the Notch2 ligands, Jagged1, 2 and DLL1, 4, were thought not to be expressed in trophoblast cell subsets of the developing mouse placenta during this time between E9.5 and E12.5, the latest investigation by Gasperowicz et al. (2013) suggests otherwise. In this study, the expression pattern of all Notch receptors and ligands were investigated from E7.5 to E12.5, during the time of mouse placental development. Notch2 and Jagged 1 and 2 were complimentarily expressed in the labyrinth layer. Meanwhile, Notch2 and DLL4 expression were shared at the decidual interface, suggesting that DLL4 could be the 'missing' ligand involved in endovascular trophoblast cell invasion mediated by Notch2 receptor signalling.

Conversely, the remaining Notch family members, including the Notch1 and 4, appear to be highly involved and crucial for fetal angiogenesis and maternal vascular formation as previously reviewed (Gasperowicz \& Otto 2008). The Notch signalling effectors, Hey $1 / 2$, are also highly expressed in the endothelial cells associated with fetal vasculature in the chorioallantoic layer that gives rise to the placental labyrinth (Fischer et al. 2004). Furthermore, double-knockout Hes/Hey mutant mice fail to undergo chorioallantoic branching during the formation of this layer (Fischer et al. 2004).

Overall, these insights from the roles of the Notch signalling family members in the formation of the functional mouse placenta could provide insight as to the potential functional roles for distinct Notch family members in various aspects of human placental development. Meanwhile, further mouse studies could elucidate the precise regulatory mechanisms of the Notch pathway during the development of the placenta.

\section{Clinical implications of inadequate implantation/placentation}

Implantation failure results in infertility and is also a major cause of unsuccessful assisted reproduction technologies such as IVF. Meanwhile, placental dysfunction is widely accepted as the underlying cause of two of the most common and severe complications of pregnancy, pre-eclampsia (PE) and intrauterine growth restriction (IUGR). These disorders contribute to significant maternal and fetal mortality and morbidity.

\section{A role for Notch in PE and IUGR}

$\mathrm{PE}$ is the single most important cause of maternal morbidity in antenatal care. PE only presents after 20 weeks of gestation (more commonly in the third trimester), although it is thought to initiate during the first trimester (Red-Horse et al. 2004, Redman \& Sargent 2005). Women who develop PE are at an increased risk of cardiovascular complications later in life (Smith et al. 2001). Some women with PE also develop IUGR (Fisher 2004). IUGR is associated with poor transformation with the maternal spiral arteries, and importantly, IUGR is the most important trigger of perinatal mortality. Moreover, low-birth-weight babies have an increased risk of developing heart disease, hypertension and diabetes in adult life (Barker \& Clark 1997).

Many studies have identified dysregulated expression of Notch family members in pre-eclamptic placentas (Cobellis et al. 2007, Sitras et al. 2009, Hunkapiller et al. 2011, Løset et al. 2011, Sahin et al. 2011, Meng et al. 2012, Taki et al. 2012). Unfortunately, in many studies, the gestational age of the samples is not matched between pre-eclamptic and control (Sitras et al. 2009, Løset et al. 2011, Meng et al. 2012). In the most recent study (Taki et al. 2012), gestational age was matched; however, the PE fetus likely also had IUGR. To date, only one study has utilized chorionic villus samples (CVS) to prospectively compare gene expression by microarray, in placentas that go on to develop PE and those that do not. No differences in expression of Notch family members were identified (Founds et al. 2009); however, the indication for the majority of women undergoing CVS was advanced maternal age, thus these tissues may be biased.

However, in placentae collected at delivery, differences have been identified in both gene (microarray) and protein (immunohistochemistry and western blotting) expression. NOTCH3 gene expression is up-regulated in pre-eclamptic placentas (Sitras et al. 2009), while Deltex 3 Homolog, HES1, NOTCH3 and $\mathrm{NOTCH} 4$ gene expression are down-regulated in the decidua of pre-eclamptic pregnancies (Johansson et al. 2011, Løset et al. 2011).

Immunolocalization of proteins suggests that there is down-regulation of many Notch family proteins in preeclamptic placentas, including Notch1 (Cobellis et al. 2007, Sahin et al. 2011), Notch2 (Sahin et al. 2011) and Notch4 (Cobellis et al. 2007, Sahin et al. 2011), Jagged1 (Cobellis et al. 2007) and Jagged2 (Sahin et al. 2011). Interestingly, this down-regulation is associated with 
a shift in protein localization from membrane-bound protein to cytoplasmic in Notch1, 2, 4 and Jagged1 (Sahin et al. 2011), possibly indicating a shift from canonical to ligand-independent Notch signalling. Notch expression in the placenta from IUGR is very similar to PE; immunostaining of Notch1, 2 and 4 and Jagged2 is reduced in the syncytiotrophoblast and the cellular localization of these receptors and ligand changes from being membrane-bound to cytoplasmic (Sahin et al. 2011).

A few studies have also identified altered expression of non-canonical Notch ligands in PE. EGF-like domain, multiple 7 (EGFL7) is down-regulated in the placenta of pre-eclamptic pregnancies (Johansson et al. 2011, Junus et al. 2012) and is further down-regulated in early-onset compared with late-onset PE (Junus et al. 2012). Nephroblastoma overexpressed (NOV) is downregulated in the placentas from early-onset PE (Gellhaus et al. 2006, 2007). Serum periostin is elevated in women with PE compared with normotensive pregnant women and is localized by in situ hybridization to stromal cells in the placenta (Sasaki et al. 2002). It should be noted that none of these studies have determined whether these proteins are signalling via Notch in these cells; however, the prevalence of Notch receptors and both canonical and non-canonical Notch ligands being dysregulated during PE does strongly suggest a role for Notch signalling in PE.

Overall, it is interesting to note that the majority of studies investigating a role for Notch signalling in PE or IUGR have focused on Notch members expression in trophoblasts. Formation and maintenance of the placental vasculature is of critical importance for normal placental formation. Many Notch proteins identified also have roles in vascularization. In the deciduas, Jagged1 immunostaining is reduced in EVTs, which have invaded maternal spiral arteries of pre-eclamptic and HELLP (haemolysis, elevated liver enzymes and low platelet count) pregnancies, regardless of the extent of remodelling (Hunkapiller et al. 2011). It should be noted that this study also shows that Jagged1 is strictly up-regulated as EVTs come into proximity of blood vessels. Thus, in a pre-eclamptic pregnancy where there is limited invasion, Jagged1 may not be up-regulated. Nevertheless, a functional role for Jagged 1 in spiral artery remodelling should be investigated, particularly as the Jagged1-null mouse shows defects in angiogenesis, although this has not been investigated in the context of placental angiogenesis (Gasperowicz \& Otto 2008).

In pre-eclamptic placentas with IUGR, DLL4 is up-regulated in the syncytiotrophoblasts and the vascular smooth muscle of the umbilical artery (Taki et al. 2012). DLL4 reduces vessel sprout length and inhibits angiogenesis and may be up-regulated in response to hypoxia (Taki et al. 2012). It is interesting that both DLL4 and Jagged 1 have been attributed to PE and poor vessel remodelling, as they are thought to antagonize one another during angiogenesis (Benedito et al. 2009). These changes in DLL4 expression are likely to represent direct effects on angiogenesis. However, these differences may reflect global changes in expression, and future studies should investigate expression in villous endothelial and associated cells, preferably from CVS sampling to allow prospective identification of protein alterations in PE and IUGR.

\section{Conclusions}

This review has summarized the currently available knowledge regarding Notch signalling during the establishment of pregnancy and highlights the role of Notch signalling during implantation and placentation. Overall, the evidence supports an important role for Notch signalling in implantation/placentation. Current data show that Notch signalling is involved in endometrial-trophectoderm interactions during the initiation of attachment, regulation of EVT invasion and spiral artery remodelling in the decidua and angiogenesis in the placenta. Furthermore, aberrant Notch signalling is found in the diseases of gestation, such as PE and IUGR.

However, our current knowledge of Notch receptor and ligand expression and functional studies investigating their role in implantation and placentation is limited. Further studies are required, particularly functional studies. The current paradigm suggests that Notch signalling is important for normal placentation and that Notch signalling may be a clinical target to improve IVF outcomes and to prevent or treat placental insufficiency.

\section{Declaration of interest}

The authors declare that there is no conflict of interest that could be perceived as prejudicing the impartiality of the review reported.

\section{Funding}

The work was supported by the Victorian Government's Operational Infrastructure Support Program. E Menkhorst was supported by a NHMRC (Australia) Early Career (Postdoctoral) Fellowship (\#611827). E Dimitriadis was supported by a NHMRC (Australia) Senior Research Fellowship (\#550905).

\section{Author contribution statement}

C Cuman and E Dimitriadis conceived the study and wrote the manuscript. E Menkhorst wrote the manuscript and designed the figure. A Winship and $M$ Van Sinderen wrote the manuscript. T Osianlis and L J Rombauts did critical analysis of the manuscript. 


\section{Acknowledgements}

The authors would like to thank Sue Pankridge for her assistance with the preparation of the manuscript figure.

\section{References}

Adjaye J, Huntriss J, Herwig R, BenKahla A, Brink TC, Wierling C, Hultschig C, Groth D, Yaspo ML, Picton HM et al. 2005 Primary differentiation in the human blastocyst: comparative molecular portraits of inner cell mass and trophectoderm cells. Stem Cells 23 1514-1525. (doi:10.1634/stemcells.2005-0113)

Afshar Y, Jeong JW, Roqueiro D, DeMayo F, Lydon J, Radtke F, Radnor R, Miele L \& Fazleabas A 2012a Notch1 mediates uterine stromal differentiation and is critical for complete decidualization in the mouse. FASEB Journal 26 282-294. (doi:10.1096/fj.11-184663)

Afshar Y, Miele L \& Fazleabas AT $2012 b$ Notch 1 is regulated by chorionic gonadotropin and progesterone in endometrial stromal cells and modulates decidualization in primates. Endocrinology 153 2884-2896. (doi:10.1210/en.2011-2122)

Aghajanova L, Shen S, Rojas AM, Fisher SJ, Irwin JC \& Giudice LC 2012 Comparative transcriptome analysis of human trophectoderm and embryonic stem cell-derived trophoblasts reveal key participants in early implantation. Biology of Reproduction 86 1-21. (doi:10.1095/ biolreprod.111.092775)

Andersen P, Uosaki H, Shenje LT \& Kwon C 2012 Non-canonical Notch signaling: emerging role and mechanism. Trends in Cell Biology 22 257-265. (doi:10.1016/j.tcb.2012.02.003)

Aplin JD 2010 Developmental cell biology of human villous trophoblast: current research problems. International Journal of Developmental Biology 54 323-329. (doi:10.1387/ijdb.082759ja)

Artavanis-Tsakonas S \& Muskavitch MA 2010 Notch: the past, the present, the future. Current Topics in Developmental Biology 92 1-29. (doi:10.1016/S0070-2153(10)92001-2)

Artavanis-Tsakonas S, Rand MD \& Lake RJ 1999 Notch signaling: cell fate control and signal integration in development. Science 284 770-776. (doi:10.1126/science.284.5415.770)

Barker DJ \& Clark PM 1997 Fetal undernutrition and disease in later life. Reviews of Reproduction 2 105-112. (doi:10.1530/ror.0.0020105)

Benedito R, Roca C, Sörensen I, Adams S, Gossler A, Fruttiger M \& Adams RH 2009 The Notch ligands DII4 and Jagged1 have opposing effects on angiogenesis. Cell 137 1124-1135. (doi:10.1016/j.cell.2009. 03.025)

Bray SJ 2006 Notch signalling: a simple pathway becomes complex. Nature Reviews. Molecular Cell Biology 7 678-689. (doi:10.1038/nrm2009)

Bray S \& Bernard F 2010 Notch targets and their regulation. Current Topics in Developmental Biology 92 253-275. (doi:10.1016/S0070-2153 (10)92008-5)

Burton GJ, Jauniaux E \& Charnock-Jones DS 2010 The influence of the intrauterine environment on human placental development. International Journal of Developmental Biology 54 303-312. (doi:10.1387/ ijdb.082764gb)

Cahill D \& Wardle P 2002 Management of infertility. BMJ 325 28-32. (doi:10.1136/bmj.325.7354.28)

Castellucci M, Kosanke G, Verdenelli F, Huppertz B \& Kaufmann P 2000 Villous sprouting: fundamental mechanisms of human placental development. Human Reproduction Update 6 485-494. (doi:10.1093/ humupd/6.5.485)

Chu PW, Wang YP, Chen IC, Pan HM \& Wu GJ 2011 Notch 1 signaling pathway effect on implantation competency. Fertility and Sterility $\mathbf{9 6}$ 1225-1229. (doi:10.1016/j.fertnstert.2011.08.032)

Cobellis L, Mastrogiacomo A, Federico E, Schettino MT, De Falco M, Manente L, Coppola G, Torella M, Colacurci N \& De Luca A 2007 Distribution of Notch protein members in normal and preeclampsiacomplicated placentas. Cell and Tissue Research 330 527-534. (doi:10.1007/s00441-007-0511-6)

Cobellis L, Caprio F, Trabucco E, Mastrogiacomo A, Coppola G, Manente L, Colacurci N, De Falco M \& De Luca A 2008 The pattern of expression of Notch protein members in normal and pathological endometrium. Journal of Anatomy 213 464-472. (doi:10.1111/j.1469-7580.2008. 00963.x)

Cormier S, Vandormael-Pournin S, Babinet C \& Cohen-Tannoudji M 2004 Developmental expression of the Notch signaling pathway genes during mouse preimplantation development. Gene Expression Patterns $\mathbf{4}$ 713-717. (doi:10.1016/j.modgep.2004.04.003)

Cox B, Kotlyar M, Evangelou A, Ignatchenko V, Ignatchenko A, Whiteley K, Jurisica I, Adamson S, Rossant J \& Kislinger T 2009 Comparative systems biology of human and mouse as a tool to guide the modeling of human placental pathology. Molecular Systems Biology 5 279-294. (doi:10.1038/msb.2009.37)

Cuman C, Menkhorst EM, Rombauts LJ, Holden S, Webster D, Bilandzic M, Osianlis T \& Dimitriadis E 2013 Preimplantation human blastocysts release factors that differentially alter human endometrial epithelial cell adhesion and gene expression relative to IVF success. Human Reproduction 28 1161-1171. (doi:10.1093/humrep/det058)

De Falco M, Cobellis L, Giraldi D, Mastrogiacomo A, Perna A, Colacurci N, Miele L \& De Luca A 2007 Expression and distribution of Notch protein members in the human placenta throughout pregnancy. Placenta 28 118-126. (doi:10.1016/j.placenta.2006.03.010)

Degaki KY, Chen Z, Yamada AT \& Croy BA 2012 Delta-like ligand (DLL)1 expression in early mouse decidua and its localization to uterine natural killer cells. PLoS ONE 7 e52037. (doi:10.1371/journal.pone.0052037)

Demir R, Seval Y \& Huppertz B 2007 Vasculogenesis and angiogenesis in the early human placenta. Acta Histochemica 109 257-265. (doi:10.1016/j.acthis.2007.02.008)

Dilworth M \& Sibley C 2013 Review: Transport across the placenta of mice and women. Placenta 34 S34-S39. (doi:10.1016/j.placenta.2012. 10.011)

Dimitriadis E, White CA, Jones RL \& Salamonsen LA 2005 Cytokines, chemokines and growth factors in endometrium related to implantation. Human Reproduction Update 11 613-630. (doi:10.1093/humupd/ dmi023)

D'Souza B, Meloty-Kapella L \& Weinmaster G 2010 Canonical and non-canonical Notch ligands. Current Topics in Developmental Biology 92 73-129. (doi:10.1016/S0070-2153(10)92003-6)

Enders A \& Carter A 2012 Review: The evolving placenta: different developmental paths to a hemochorial relationship. Placenta 33 S92-S98. (doi:10.1016/j.placenta.2011.10.009)

Fisher SJ 2004 The placental problem: linking abnormal cytotrophoblast differentiation to the maternal symptoms of preeclampsia. Reproductive Biology and Endocrinology 2 53. (doi:10.1186/1477-7827-2-53)

Fischer A, Schumacher N, Maier M, Sendtner M \& Gessler M 2004 The Notch target genes Hey1 and Hey2 are required for embryonic vascular development. Genes and Development 18 901-911. (doi:10.1101/gad. 291004)

Founds SA, Conley YP, Lyons-Weiler JF, Jeyabalan A, Hogge WA \& Conrad KP 2009 Altered global gene expression in first trimester placentas of women destined to develop preeclampsia. Placenta 30 15-24. (doi:10.1016/j.placenta.2008.09.015)

Gasperowicz M \& Otto F 2008 The Notch signalling pathway in the development of the mouse placenta. Placenta 29 651-659. (doi:10.1016/j.placenta.2008.06.004)

Gasperowicz M, Rai A \& Cross JC 2013 Spatiotemporal expression of Notch receptors and ligands in developing mouse placenta. Gene Expression Patterns 13 249-254. (doi:10.1016/j.gep.2013.04.006)

Gellhaus A, Schmidt M, Dunk C, Lye SJ, Kimmig R \& Winterhager E 2006 Decreased expression of the angiogenic regulators CYR61 (CCN1) and NOV (CCN3) in human placenta is associated with pre-eclampsia. Molecular Human Reproduction 12 389-399. (doi:10.1093/molehr/ gal044)

Gellhaus A, Schmidt M, Dunk C, Lye SJ \& Winterhager E 2007 The circulating proangiogenic factors CYR61 (CCN1) and NOV (CCN3) are significantly decreased in placentae and sera of preeclamptic patients. Reproductive Sciences 14 46-52. (doi:10.1177/1933719107309816)

Hamada Y, Kadokawa Y, Okabe M, Ikawa M, Coleman JR \& Tsujimoto Y 1999 Mutation in ankyrin repeats of the mouse Notch2 gene induces early embryonic lethality. Development 126 3415-3424.

Hamada Y, Hiroe T, Suzuki Y, Oda M, Tsujimoto Y, Coleman JR \& Tanaka S 2007 Notch2 is required for formation of the placental circulatory 
system, but not for cell-type specification in the developing mouse placenta. Differentiation 75 268-278. (doi:10.1111/j.1432-0436.2006. 00137.x)

Harris LK 2011 IFPA Gabor Than Award lecture: Transformation of the spiral arteries in human pregnancy: key events in the remodelling timeline. Placenta 32 S154-S158. (doi:10.1016/j.placenta.2010.11.018)

Herr F, Schreiner I, Baal N, Pfarrer C \& Zygmunt M 2011 Expression patterns of Notch receptors and their ligands Jagged and Delta in human placenta. Placenta 32 554-563. (doi:10.1016/j.placenta.2011. 04.018)

Hess AP, Hamilton AE, Talbi S, Dosiou C, Nyegaard M, Nayak N, Genbecev-Krtolica O, Mavrogianis P, Ferrer K, Kruessel J et al. 2007 Decidual stromal cell response to paracrine signals from the trophoblast: amplification of immune and angiogenic modulators. Biology of Reproduction 76 102-117. (doi:10.1095/biolreprod.106. 054791)

Hunkapiller NM, Gasperowicz M, Kapidzic M, Plaks V, Maltepe E, Kitajewski J, Cross JC \& Fisher SJ 2011 A role for Notch signaling in trophoblast endovascular invasion and in the pathogenesis of pre-eclampsia. Development 138 2987-2998. (doi:10.1242/dev. 066589)

Hurlbut GD, Kankel MW, Lake RJ \& Artavanis-Tsakonas S 2007 Crossing paths with Notch in the hyper-network. Current Opinion in Cell Biology 19 166-175. (doi:10.1016/j.ceb.2007.02.012)

Ilagan MX \& Kopan R 2007 SnapShot: notch signaling pathway. Cell 128 1246. (doi:10.1016/j.cell.2007.03.011)

Johansson Å, Løset M, Mundal S, Johnson M, Freed K, Fenstad M, Moses E, Austgulen R \& Blangero J 2011 Partial correlation network analyses to detect altered gene interactions in human disease: using preeclampsia as a model. Human Genetics 129 25-34. (doi:10.1007/s00439-0100893-5)

Junus K, Centlow M, Wikström A-K, Larsson I, Hansson SR \& Olovsson M 2012 Gene expression profiling of placentae from women with early- and late-onset pre-eclampsia: down-regulation of the angiogenesis-related genes ACVRL1 and EGFL7 in early-onset disease. Molecular Human Reproduction 18 146-155. (doi:10.1093/ molehr/gar067)

Kaufmann P, Bruns U, Leiser R, Luckhardt M \& Winterhager E 1985 The fetal vascularisation of term human placental villi II. Intermediate and terminal villi. Anatomy and Embryology 173 203-214. (doi:10.1007/ BF00316301)

Knofler M 2010 Critical growth factors and signalling pathways controlling human trophoblast invasion. International Journal of Developmental Biology 54 269-280. (doi:10.1387/ijdb.082769mk)

Koot YE, Boomsma CM, Eijkemans MJ, Lentjes EG \& Macklon NS 2011 Recurrent pre-clinical pregnancy loss is unlikely to be a 'cause' of unexplained infertility. Human Reproduction 26 2636-2641. (doi:10.1093/ humrep/der217)

Kopan R \& Ilagan MX 2009 The canonical Notch signaling pathway: unfolding the activation mechanism. Cell 137 216-233. (doi:10.1016/ j.cell.2009.03.045)

Leong KG \& Karsan A 2006 Recent insights into the role of Notch signaling in tumorigenesis. Blood $\mathbf{1 0 7}$ 2223-2233. (doi:10.1182/blood-200508-3329)

Løset M, Mundal SB, Johnson MP, Fenstad MH, Freed KA, Lian IA, Eide IP, Bjørge L, Blangero J, Moses EK et al. 2011 A transcriptional profile of the decidua in preeclampsia. American Journal of Obstetrics and Gynecology 204 84.e1-84.e27. (doi:10.1016/j.ajog.2010.08.043)

Lunghi L, Ferretti M, Medici S, Biondi C \& Vesce F 2007 Control of human trophoblast function. Reproductive Biology and Endocrinology 56. (doi:10.1186/1477-7827-5-6)

Manaster I, Gazit R, Goldman-Wohl D, Stern-Ginossar N, Mizrahi S, Yagel S \& Mandelboim O 2010 Notch activation enhances IFN $\gamma$ secretion by human peripheral blood and decidual NK cells. Journal of Reproductive Immunology 84 1-7. (doi:10.1016/j.jri.2009. 10.009)

Mazella J, Liang S \& Tseng L 2008 Expression of Delta-like protein 4 in the human endometrium. Endocrinology 149 15-19. (doi:10.1210/en. 2007-0477)

Meng T, Chen H, Sun M, Wang H, Zhao G \& Wang X 2012 Identification of differential gene expression profiles in placentas from preeclamptic pregnancies versus normal pregnancies by DNA microarrays. OMICS: a Journal of Integrative Biology 16 301-311. (doi:10.1089/omi.2011. 0066)

Mikhailik A, Mazella J, Liang S \& Tseng L 2009 Notch ligand-dependent gene expression in human endometrial stromal cells. Biochemical and Biophysical Research Communications 388 479-482. (doi:10.1016/ j.bbrc.2009.07.037)

Mitsuhashi Y, Horiuchi A, Miyamoto T, Kashima H, Suzuki A \& Shiozawa T 2012 Prognostic significance of Notch signalling molecules and their involvement in the invasiveness of endometrial carcinoma cells. Histopathology 60 826-837. (doi:10.1111/j.1365-2559.2011.04158.x)

Mori M, Miyamoto T, Ohno S, Miyake Y, Sakaguchi T \& Ohno E 2012 Diagnostic utility of Notch-1 immunocytochemistry in endometrial cytology. Acta Cytologica 56 166-170. (doi:10.1159/000335485)

Murata A, Okuyama K, Sakano S, Kajiki M, Hirata T, Yagita H, ZúñigaPflücker JC, Miyake K, Akashi-Takamura S, Moriwaki S et al. 2010 A Notch ligand, Delta-like 1 functions as an adhesion molecule for mast cells. Journal of Immunology 185 3905-3912. (doi:10.4049/jimmunol. 1000195)

Norwitz ER, Schust DJ \& Fisher SJ 2001 Implantation and the survival of early pregnancy. New England Journal of Medicine 345 1400-1408. (doi:10.1056/NEJMra000763)

Paiva P, Menkhorst E, Salamonsen LA \& Dimitriadis E 2009 Leukemia inhibitory factor and interleukin-11: critical regulators in the establishment of pregnancy. Cytokine \& Growth Factor Reviews 20 319-328. (doi:10.1016/j.cytogfr.2009.07.001)

Popovici RM, Kao L-C \& Giudice LC 2000 Discovery of new inducible genes in in vitro decidualized human endometrial stromal cells using microarray technology. Endocrinology 141 3510-3515. (doi:10.1210/ en.141.9.3510)

Red-Horse K, Zhou Y, Genbacev O, Prakobphol A, Foulk R, McMaster M \& Fisher SJ 2004 Trophoblast differentiation during embryo implantation and formation of the maternal-fetal interface. Journal of Clinical Investigation 114 744-754. (doi:10.1172/JCI200422991)

Redman CW \& Sargent IL 2005 Latest advances in understanding preeclampsia. Science 308 1592-1594. (doi:10.1126/science. 1111726)

Robson A, Harris LK, Innes BA, Lash GE, Aljunaidy MM, Aplin JD, Baker PN, Robson SC \& Bulmer JN 2012 Uterine natural killer cells initiate spiral artery remodeling in human pregnancy. FASEB Journal $\mathbf{2 6}$ 4876-4885. (doi:10.1096/fj.12-210310)

Sahin Z, Acar N, Ozbey O, Ustunel I \& Demir R 2011 Distribution of Notch family proteins in intrauterine growth restriction and hypertension complicated human term placentas. Acta Histochemica 113 270-276. (doi:10.1016/j.acthis.2009.10.006)

Salamonsen LA, Nie G, Hannan NJ \& Dimitriadis E 2009 Society for Reproductive Biology Founders' Lecture 2009. Preparing fertile soil: the importance of endometrial receptivity. Reproduction, Fertility, and Development 21 923-934. (doi:10.1071/RD09145)

Sasaki H, Roberts J, Lykins D, Fujii Y, Auclair D \& Chen L 2002 Novel chemiluminescence assay for serum periostin levels in women with preeclampsia and in normotensive pregnant women. American Journal of Obstetrics and Gynecology 186 103-108. (doi:10.1067/mob. 2002.118157)

Scott RT, Upham KM, Forman EJ, Hong KH, Scott KL, Taylor D, Tao X \& Treff NR 2013 Blastocyst biopsy with comprehensive chromosome screening and fresh embryo transfer significantly increases in vitro fertilization implantation and delivery rates: a randomized control trial. Fertility and Sterility 100 697-703. (doi:10.1016/j.fertnstert.2013.04. 035)

Seval Y, Korgun ET \& Demir R 2007 Hofbauer cells in early human placenta: possible implications in vasculogenesis and angiogenesis. Placenta 28 841-845. (doi:10.1016/j.placenta.2007.01.010)

Sitras V, Paulssen RH, Grønaas H, Leirvik J, Hanssen TA, Vårtun A \& Acharya G 2009 Differential placental gene expression in severe preeclampsia. Placenta 30 424-433. (doi:10.1016/j.placenta.2009. 01.012)

Smith GC, Pell JP \& Walsh D 2001 Pregnancy complications and maternal risk of ischaemic heart disease: a retrospective cohort study of 129,290 births. Lancet 357 2002-2006. (doi:10.1016/S0140-6736 (00)05112-6) 
Taki A, Abe M, Komaki M, Oku K, Iseki S, Mizutani S \& Morita I 2012 Expression of angiogenesis-related factors and inflammatory cytokines in placenta and umbilical vessels in pregnancies with preeclampsia and chorioamnionitis/funisitis. Congenital Anomalies 52 97-103. (doi:10.1111/j.1741-4520.2012.00359.x)

Wang MM 2011 Notch signaling and Notch signaling modifiers. International Journal of Biochemistry \& Cell Biology 43 1550-1562. (doi:10.1016/j.biocel.2011.08.005)

Watson E \& Cross J 2005 Development of structures and transport functions in the mouse placenta. Physiology 20 180-193. (doi:10.1152/physiol. $00001.2005)$

Yu X, Zou J, Ye Z, Hammond H, Chen G, Tokunaga A, Mali P, Li Y-M, Civin C, Gaiano N et al. 2008 Notch signaling activation in human embryonic stem cells is required for embryonic, but not trophoblastic, lineage commitment. Cell Stem Cell 2 461-471. (doi:10.1016/j.stem. 2008.03.001)

Zhao WX \& Lin JH 2012 Notch signaling pathway and human placenta. International Journal of Medical Sciences 9 447-452. (doi:10.7150/ ijms.4593)

Received 24 September 2013

First decision 25 November 2013

Revised manuscript received 2 December 2013

Accepted 19 December 2013 